\title{
THE EFFECT OF SHIFT TIME AND WORK SCHEDULE ON INJURIES IN THE INDUSTRIAL WORKPLACE
}

\author{
Joshua Pralli, \\ Michael Ross ${ }^{2}$ \\ 1PT, DPT, EdD, MS, OCS, \\ Department of Physical Therapy, \\ University of Scranton, \\ 237 Jefferson Avenue, Scranton, PA 18510, \\ USA \\ 2Physical Therapy Department, \\ Daemen College, 4380 Main St, \\ Amherst, NY 14226, \\ USA
}

\begin{abstract}
:
Background: Musculoskeletal injuries have increased in the past decade and to date, no study has examined an employee work schedule and shift time on injuries. Aims: The purpose of this study was to examine the impact an employees' shift time and work schedule have on occupational injuries in the industrial workplace. Setting and Design: Retrospective analysis of a large manufacturing company located in Northeastern Pennsylvania. The company employs 551 workers for work on assembly lines, packaging products, dissemination of old material, loading and unloading delivery trucks, and cleaning between two locations. Methods and Materials: Occupational injuries were gathered from analysis of the company's Occupational Safety and Health Administration 300 Injury and Illness Log from 2016 to 2020. A retrospective analysis of injured employees $(N=143)$ over a five-year period from 2016-2020. Statistical Analysis: A chisquare analysis was used to analysis how work shift and work schedule impacted injuries $(p<0.005)$. Results: The results of the study add significant information to the existing literature on ergonomic interventions in the industrial workplace being delivered by a physical therapist. The results indicate that there is a statistically significant relationship between an employee's shift time and a non-statistically positive association between an employee's work schedule on injuries. Researchers found that employees are being injured more in the second half of the workday and later in the employee's work week. Conclusion: The authors conclude that shift time and work schedule are important factors for reducing injuries in the workplace.
\end{abstract}

Keywords: physical therapy, injury prevention, ergonomics, injuries, and safety

i Correspondence: email joshua.prall@scranton.edu 


\section{Introduction}

Work-related musculoskeletal disorders (WMSDs) are injuries to the musculoskeletal system that occurs in the industrial workplace due to movements that include bending at the waist, twisting the spine, and pulling and pushing heavy objects ${ }^{1}$. The industrial workplace has shown an increase in number of recordable injuries per year over the past ten years, and a recent report by Liberty Mutual Insurance revealed that in 201918.1 billion dollars per year are spent on overexertion injuries typically seen in an industrial workplace setting ${ }^{2}$. The Bureau of Labor Statistics (BLS) reported 2.9 million non-fatal injuries in 2018 and 30\% were classified as repetitive motion injuries, which are highly reported in the industrial workplace ${ }^{3}$. There have been many empirical studies on the effects of ergonomics and injuries when the intervention has been specifically delivered by a physical therapist ${ }^{4-7}$. Physical therapists have the education and training to champion the campaign of healthcare providers who can reduce costs and injuries in the industrial workplace through ergonomic interventions ${ }^{8}$.

There have been many studies throughout the past decade that examine ergonomics interventions and the effect on the industrial workplace setting. When ergonomic interventions were applied, employers saw: (a) decreased injuries, (b) increased productivity, (c) decreased costs associated with direct and indirect costs of work-related injuries, (d) improvements in return-to-work performance, and (e) decreased absenteeism in employees ${ }^{8-10}$. However, the major limitation in these studies is they do not investigate a primary healthcare provider to champion this process. These studies also do not identify external factors, like an employee's shift time and work schedule, on WMSDs. A recent systematic review by Luger, Maher, Rieger, \& Steinhilber ${ }^{11}$ found that work-break schedules played a significant role in reducing injuries and suggested that other variables, like work schedule and shift times could also play a large role in injuries in the industrial workplace. In response, the purpose of this study will be to conduct a retrospective analysis of archival data to determine the effects of shift time and work schedule on injuries in the industrial workplace. The ergonomic interventions and analysis were performed by a licensed physical therapist. We hypothesize that injuries will occur later in the work week and later in the workday for employees who are involved in a WMSDs.

\section{Methods and Materials}

Data for this retrospective analysis was obtained from a large manufacturing company located in the Northeastern portion of the United States. The company currently employs 551 workers and hired between 85-100 new employees in each of the years between 20162020. Industrial workers are hired for assembly lines, packaging products, dissemination of old material, loading and unloading delivery trucks, and cleaning between two locations in the Northeast. These jobs are highly rigorous and involve four 12-hour shifts consisting of repetitive motions and heavy lifting throughout the entire shift. Repetitive 
motions for these jobs include lifting, bending, performing overhead activities, twisting, pushing, pulling, and torqueing.

The instrumentation used for this study included the OSHA 300 Injury and Illness Log. For this study, all completed OSHA 300 Injury and Illness Logs that were recorded between 2016-2020 were used for the data analysis. The use of this instrument allowed for the researchers to include only injuries at work that were the result of a sprain, strain, pull, push, or overexertion injury to the musculoskeletal system. This also included any catastrophic or non-muscular injuries in the workplace. All OSHA 300 Log completions were performed by certified safety professionals. The type of injuries reported by employees were organized into ten categories: amputations, burns, concussions, contusions, carpal tunnel syndrome, fractures, infections, lacerations, sprains, and strains. WMSDs included concussions, carpal tunnel syndrome, sprains, and strains were due to repetitive motions causing stress on the musculoskeletal system from bending, twisting, lifting, pushing, pulling, and torquing.

During the fall of the 2020 fiscal year, the researcher collected the archival data from the company. The analysis was performed by a licensed physical therapist. This study was approved by the Institutional Review Board (IRB) at a Pennsylvania State System of Higher Education (PASSHE). All participants involved in the study signed consent forms prior to employment to inform them that if they are injured, the injury will be recorded using the OSHA $300 \mathrm{log}$. All employees are aware that data may be shared and used by researchers for data analysis.

\subsection{Data Analysis}

The Statistical Product and Service Solutions (SPSS) was used for data analysis. Descriptive statistics were used to characterize subjects and work-related injuries. First, a chi-square for association was conducted between shift time and injuries in the workplace from 2016-2020. Next, a chi-square for association was conducted between work schedule and injuries in the workplace from 2016-2020.

\section{Results}

Participants for this study included male and female workers $(n=143)$ with ages ranging from 22-64 who are working full-time in an industrial setting at a building products manufacturing plant in northeastern Pennsylvania. Out of all the participants $80 \%$ are Caucasian, $14 \%$ are African American, and $6 \%$ are Latino or Hispanic. Seventy-seven percent of the injured workers are male and $23 \%$ are female. Less than 5 percent of the participants have completed high school and have obtained a bachelor's degree, $80 \%$ have graduated high school only, and $15 \%$ of the participants did not graduate high school. Marital status includes 39\% married and 61\% single. The types of injuries and the frequency of occurrence are listed in Table 2.

There was a statistically significant association between shift time and injuries in the workplace, $x^{2}(1)=25.632, p=0.001$. There was a moderately strong association between shift time and injuries in the workplace, $\varphi=0.423, p=0.001$. There was not a 
statistically significant association between work schedule and injuries in the workplace, $\mathrm{x}^{2}(1)=26.438, \mathrm{p}=0.190$. However, there was a moderately strong non-statistical positive association between shift time and injuries in the workplace, $\varphi=0.423, p=0.190$. Further analysis of data showed that that there was an increase in the number of injuries later in the workday and later in the work week from 2016-2020 as seen in Tables 19 and 20.

\subsection{General Overview}

There has been a reduction in injuries, both musculoskeletal and non-musculoskeletal across the span of five years. Moreover, there was a reduction of injuries and a reduction in costs associated with injuries once ergonomic interventions were implemented by way of an ergonomic consultant, who is a physical therapist. Ergonomic interventions include: (a) education, (b) lifting mechanics, (c) postural training, (d) stretching exercises, (e) strengthening exercises, (f) return-to-work programs, and (g) job site assessments. The ergonomic interventions were performed at both locations in the Northeast. From 20162017, the intervention of education was provided yearly. From 2018-2019, ergonomic interventions consisting of education, job site assessments, lifting mechanics, postural training, and return-to-work were performed. In 2020, the addition of stretching exercises and strengthening exercises were added to the list of current ergonomic interventions.

\subsection{Shift Time and Work Schedule}

To answer the question of the impact of shift time and work schedule on injuries in the workplace, statistical analyses were performed. First, a chi-square for association was conducted between shift time and injuries in the workplace from 2016-2020. There was a statistically significant association between shift time and injuries in the workplace, $\mathrm{x}^{2}(1)$ $=25.632, \mathrm{p}=0.001$. There was a moderately strong association between shift time and injuries in the workplace, $\varphi=0.423, p=0.001$. Next, a chi-square for association was conducted between work schedule and injuries in the workplace from 2016-2020. There was not a statistically significant association between day of shift and injuries in the workplace, $x^{2}(1)=26.438, p=0.190$. There was a moderately strong non-statistical positive association between shift time and injuries in the workplace, $\varphi=0.423, p=0.190$. An analysis of data showed that that there was an increase in the number of injuries later in the workday and later in the work week from 2016-2020 as seen in Tables 19 and 20.

\section{Discussion}

Ergonomics and its effects on injuries in the workplace have been studied since the early 1970s when OSHA was founded ${ }^{12}$. Several important intervention studies, literature reviews, systematic reviews, and meta-analyses have been performed over the past 10 years specifically investigating the effects of physical therapy delivered ergonomic interventions on injuries alone in the workplace, ${ }^{4,10,13-26}$. Very few studies involving physical therapy delivered ergonomic interventions have examined external variables such as shift time and work schedule on injuries in the industrial workplace ${ }^{15,18,20,26}$. Studies that have been performed investigating the effects of ergonomic intervention as 
the independent variable and injuries in the workplace as the dependent variable, have been reliable studies where the result has been overwhelmingly positive that when ergonomic interventions have been applied in an industrial workplace, the end result is a reduction in injuries. To expand on the current body of literature on physical therapy delivered ergonomic intervention in an industrial workplace setting, authors examined variables of shift time and work schedule on injuries in the workplace. This study is important for physical therapists and healthcare professionals delivering ergonomic interventions, as well as researchers and employers to expand on the current body of literature and add valuable information that will help even further in the reduction of injuries and associated costs of injuries in the workplace.

As a result of this retrospective analysis, two main data driven implications for physical therapists and healthcare providers who provide ergonomic interventions in an industrial workplace have risen. Implications for business owners who are actively searching for important methods to decrease injuries and costs in the industrial workplace also exist.

First, physical therapists and healthcare providers must include shift time into their data collection when building background information for a company prior to providing ergonomic services. To date, there has not been any scholarly research involving shift time as a potential variable that can explain increased injuries in the workplace. The employees for this company worked four, 12-hour workdays, and shift time was divided into two components; the first 6 hours of work and the last 6 hours of work. The implication is that researchers need to be aware of when injuries are happening within an employee's shift so that the person providing the ergonomic services is aware and can log when the injuries are happening to look for patterns in the injuries that are occurring and the type of injuries that are occurring during those times. The current study had a statistically significant association $(\mathrm{P}<0.05)$ between shift time and injuries in the workplace. Specifically, $72.8 \%$ of the injuries that occurred between 2016-2020 occurred in the second 6 hours of work. This will provide physical therapists and healthcare professionals more in-depth knowledge about the injuries that are occurring at work and be able to make recommendations to the company to reduce injuries and costs.

Second, physical therapists and healthcare providers must also include an employee's work schedule as a potential variable for increased injuries in the workplace. Like shift time, to date there has not been any data analysis in the literature that includes an employee's work schedule as a potential variable for injuries. The implication is that researchers need to be aware of when injuries are happening within an employee's work schedule, so that the person providing the ergonomic services can track work schedules and develop a pattern of work injuries. The current study did not have a statistically significant association $(\mathrm{P}>0.05)$ between work schedule and injuries in the workplace. However, the analysis of data showed that $50.3 \%$ of the injuries that occurred between 2016-2020 occurred during the last day of an employee's work schedule. The data also showed that $31.8 \%$ of the injuries that occurred between 2016-2020 occurred during the second to last day of their work schedule. This means $82.1 \%$ of the injuries that occurred between the five-year span occurred during the last two days of an employee's work 
week. Current scholarly research by Skamagki et al. ${ }^{10}$ states that workers are likely injured due to muscular fatigue, leading to poor body mechanics, resulting in an injury from a repetitive motion. The current findings from this study suggest that the second half of the workday and later in the work week contributed to a majority of injuries between 2016-2020, likely from fatigue. Like shift time, this implication will allow physical therapists and healthcare professionals more in-depth knowledge about the injuries that are occurring at work and be able to make recommendations to the company to reduce injuries and costs.

\section{Conclusion}

The purpose of this retrospective analysis was to examine the impact of an employee's shift time and work schedule on injuries. The results were based on existing data of injured employee's $(\mathrm{N}=143)$ over a five-year period from 2016-2020. The results indicate that there is a statistically significant relationship between an employee's shift time and injuries. There was also a statistically non-significant positive association between an employee's work schedule and injuries in the workplace. This study showed that employees in the industrial workplace were injured more at the end of their workday and end of their work week. This retrospective analysis provides physical therapists who are providing ergonomic interventions in an industrial workplace with new data to increase awareness to the field on the effects ergonomics has in the workplace and provides a framework for future studies for physical therapy delivered ergonomic interventions.

\subsection{Recommendations}

Based on the findings of the study it is hereby recommended that an employee's shift time and overall work schedule should be considered as variables that occupational health professionals need to consider when employing workplace injury prevention programs to employers.

\section{Conflict of Interests}

The authors declare no conflict of interests.

\section{About the Authors}

Joshua Prall, PT, DPT, EdD, MS, OCS is the owner of Coastal Consulting LLC, specializing in providing ergonomics education and workplace safety programs which benefit both the employees and the employers to reduce workplace injuries, increase productivity, and decrease spending on healthcare costs. He is a Board-Certified Orthopedic Physical Therapist through the American Board of Physical Therapy Specialties (ABPTS). He is an adjunct professor at the University of Scranton and Misericordia University where he is active teaching in the Occupational Health, Therapeutic Exercise, Grand Rounds, and Orthopedic Physical Therapy curriculums. He has guest lectured on ergonomics and work hardening at various universities including 
Bloomsburg University of Pennsylvania on the topic ergonomic consulting to reduce workplace injuries in the Master of Athletic Training Program and internationally on topics including ergonomics and postural training for the Master of Science in Physiotherapy Program at the Bangladesh Health Professions Institute. He is a member of the American Physical Therapy Association (APTA) and is a member of the Orthopedic, Research, and Health Policy and Administration sections. He is also a member of the Occupational Health Special Interest Group (OHSIG) through the Academy of Orthopedic Physical Therapy (AOPT) and is currently serving as Vice Research Chair for the OHSIG. He has also published multiple manuscripts in peerreviewed journals on the effects physical therapy delivered workplace injury prevention and ergonomics on injury reduction and costs in the workplace.

Michael Ross, PT, DHSc, OCS, FAAOMPT is an Assistant Professor in the Department of Physical Therapy at Daemen College in Amherst NY. He is a board-certified Orthopedic Clinical Specialist from the American Board of Physical Therapy Specialties and a Fellow of the American Academy of Orthopedic Manual Physical Therapists. Prior to his appointment at Daemen College, Dr. Ross served in the U.S. Air Force for 20 years where he was credentialed as a direct access provider with diagnostic imaging and pharmacological privileges. He completed his Bachelor's of Science in Physical Therapy from Daemen College, his Doctorate of Health Science in Physical Therapy from the University of Indianapolis, and a Fellowship in Orthopedic Manual Therapy and Musculoskeletal Primary Care from Kaiser Permanente Medical Center in Vallejo, CA. He has made numerous scientific presentations and has lectured extensively at the entrylevel, graduate, and postgraduate levels on medical screening and differential diagnosis in physical therapist practice. Dr. Ross maintains a pro bono practice for community residents and has published over 150 manuscripts and abstracts related to orthopedic physical therapist practice. He served as the Editor for the Musculoskeletal Imaging feature of the Journal of Orthopaedic and Sports Physical Therapy from 2008 to 2016 and is a manuscript reviewer for several medical and rehabilitation journals.

\section{References}

1. Industry Injury and Illness Data. U.S. Bureau of Labor Statistics. https://www.bls.gov/iif/oshsum.htm. Published November 4, 2020. Accessed December 31, 2020.

2. Department of Labor logo United States Department of Labor. Law and Regulations I Occupational Safety and Health Administration. https://www.osha.gov/laws-regs. Accessed December 31, 2020.

3. Industry Injury and Illness Data. U.S. Bureau of Labor Statistics. https://www.bls.gov/iif/oshsum.htm. Published November 4, 2020. Accessed December 31, 2020. 
4. Chen X, Coombes BK, Sjøgaard G, Jun D, O'Leary S, Johnston V. Workplace-based interventions for neck pain in office workers: Systematic review and metaanalysis. Physical Therapy. 2018;98(1):40-62. https://doi.org/10.1093/ptj/pzx101

5. Chetty L. The role of physiotherapy in occupational health rehabilitation: A review of the literature. Indian Journal of Physiotherapy and Occupational Therapy - An International Journal. 2013;7(4):118-122. https://doi.org/10.5958/j.0973-5674.7.4.133

6. Chetty L. Physiotherapy and ergonomics for a work-related musculoskeletal disorder. International Journal of Therapy and Rehabilitation. 2010;17(2):84-91. doi:10.12968/ijtr.2010.17.2.46334.

7. Shariat A, Cleland JA, Danaee M, Kargarfard M, Sangelaji B, Tamrin SB. Effects of stretching exercise training and ergonomic modifications on musculoskeletal discomforts of office workers: A randomized controlled trial. Brazilian Journal of Physical Therapy. 2018;22(2):144-153. https://doi.org/10.1016/j.bjpt.2017.09.003

8. Padula RS, Oliveira AB, Carregaro RL, Sato TO. Physical therapy in occupational health and ergonomics: Practical applications and innovative research approaches. Brazilian Journal of Physical Therapy. 2016;20(5):490-492. https://doi.org/10.1590/bjpt-rbf.2014.0193

9. Cecil R, Ross M. Effective worksite strategies and interventions to increase physical activity in sedentary workforce populations: The role of the physical therapists. Orthopaedic Practice. 2018;29(1):56-62

10. Skamagki G, King A, Duncan M, Wåhlin C. A systematic review on workplace interventions to manage chronic musculoskeletal conditions. Physiotherapy Research International. 2018;23(4):e1738. https://doi.org/10.1002/pri.1738

11. Luger T, Maher CG, Rieger MA, Steinhilber B. Work-break schedules for preventing musculoskeletal symptoms and disorders in healthy workers. Cochrane Database of Systematic Reviews. 2019. doi:10.1002/14651858.cd012886.pub2.

12. Silverstein M. Getting Home Safe and Sound: Occupational Safety and Health Administration at 38. American Journal of Public Health. 2008;98(3):416-423. doi:10.2105/ajph.2007.117382.

13. Ahlstrom L, Hagberg M, Dellve L. Workplace rehabilitation and supportive conditions at work: A prospective study. Journal of Occupational Rehabilitation. 2012;23(2):248-260. https://doi.org/10.1007/s10926-012-9391-z

14. Alabdulkarim S, Nussbaum MA, Rashedi E, Kim S, Agnew M, Gardner, R. Impact of task design on task performance and injury risk: case study of a simulated drilling task. Ergonomics. 2016;60(6):851-866. https://doi.org/10.1080/00140139.2016.1217354

15. Engberg JB, Harris-Shapiro J, Hines D, McCarver P, Liu, HH. The Impact of worksite clinics on teacher health care utilization and cost, self-reported health status, and student academic achievement growth in a public school district. Journal of Occupational and Environmental Medicine. 2018;60(8):1-78. https://doi.org/10.1097/jom.0000000000001373

16. Esmaeilzadeh S, Ozcan E, Capan N. Effects of ergonomic intervention on workrelated upper extremity musculoskeletal disorders among computer workers: a 
randomized controlled trial. International Archives of Occupational and Environmental Health. 2012;87(1):73-83. https://doi.org/10.1007/s00420-012-0838-5

17. Etuknwa AB, Humpheries S. A systematic review on the effectiveness of ergonomic training intervention in reducing the risk of musculoskeletal disorder. J Nurs Health Stud. 2018;3(2):1-10. https://doi.org/10.21767/2574-2825.1000032

18. Hoeben C, Louw Q. Ergonomic chair intervention: Effect on chronic upper quadrant dysfunction, disability and productivity in female computer workers. South African Journal of Physiotherapy. 2014;70(2). doi:10.4102/sajp.v70i2.32

19. Jaromi M, Nemeth A, Kranicz J, Laczko T, Betlehem, J. Treatment and ergonomics training of work-related lower back pain and body posture problems for nurses. Journal of Clinical Nursing. 2012;21(11-12):1776-1784. https://doi.org/10.1111/j.1365-2702.2012.04089.x

20. Kennedy CA, Iii BCA, Dennerlein JT, et al. Systematic Review of the Role of Occupational Health and Safety Interventions in the Prevention of Upper Extremity Musculoskeletal Symptoms, Signs, Disorders, Injuries, Claims and Lost Time. Journal of Occupational Rehabilitation. 2009;20(2):127-162. doi:10.1007/s10926009-9211-2.

21. Kim SE, Chun JC, Hong J. Ergonomics interventions as a treatment and preventative tool for work-related musculoskeletal disorders. International Journal of Caring Sciences. 2013;6(3):339-348.

22. Leyshon R, Chalova K, Gerson L, Savtchenko A, Zakrzewski R, Howie A, Shaw L. Ergonomic interventions for office workers with musculoskeletal disorders: A systematic review. Work. 2010;35:335-348.

23. Mehrparvar AH, Heydari M, Mirmohammadi, SJ, Mostaghaci M, Davari MH, Taheri M Ergonomic intervention, workplace exercises and musculoskeletal complaints: A comparative study. Med J Islam Repub Iran. 2014;28(69):1-8.

24. Noh H, Roh, H. Approach of industrial physical therapy to assessment of the musculoskeletal system and ergonomic risk factors of the dental hygienist. Journal of Physical Therapy Science. 2013;25(7):821-826. https://doi.org/10.1589/jpts.25.821

25. Shariat A, Cleland JA, Danaee M, Kargarfard M, Sangelaji B, Tamrin SB. Effects of stretching exercise training and ergonomic modifications on musculoskeletal discomforts of office workers: A randomized controlled trial. Brazilian Journal of Physical Therapy. 2018;22(2):144-153. https://doi.org/10.1016/j.bjpt.2017.09.003

26. Tompa E, Dolinschi R, Oliveira CD, Amick BC, Irvin E. A systematic review of workplace ergonomic interventions with economic analyses.Journal of Occupational Rehabilitation. 2018:20(2);220-234. https://doi.org/10.1007/s10926-009$\underline{9210-3}$ 


\section{Appendices}

Table A.1: Shift Time Total Injuries from 2016-2020

\begin{tabular}{lc}
\hline Shift Time & N \\
\hline First 6 hours & 33 \\
\hline Second 6 hours & 110 \\
\hline Total & 143 \\
\hline
\end{tabular}

Table A.2: Day of Shift Total Injuries from 2016-2020

\begin{tabular}{lccccc}
\hline Injury Type & $\mathbf{1}^{\text {st }}$ Day & $\mathbf{2}^{\text {nd }}$ Day & $\mathbf{3}^{\text {rd }}$ Day & $\mathbf{4}^{\text {th }}$ Day & Total \\
\hline Laceration & 2 & 2 & 12 & 17 & 33 \\
Concussion & 1 & 0 & 1 & 4 & 6 \\
\hline Sprain & 2 & 8 & 14 & 31 & 55 \\
Fracture & 0 & 1 & 11 & 7 & 19 \\
Burn & 0 & 1 & 2 & 3 & 6 \\
\hline Contusion & 1 & 0 & 5 & 10 & 16 \\
Strain & 0 & 0 & 0 & 4 & 4 \\
Other & 1 & 0 & 3 & 0 & 4 \\
Total & 7 & 12 & 48 & 76 & 143 \\
\hline
\end{tabular}

Table A.3: Ergonomic Interventions and Total Injuries Recorded from 2016-2020

\begin{tabular}{lccccc}
\hline Injury Type & Education & $\begin{array}{c}\text { Ed, JSA, } \\
\text { LM }\end{array}$ & $\begin{array}{c}\text { Ed, JSA, LM, } \\
\text { PT, RTW }\end{array}$ & $\begin{array}{c}\text { Ed, JSA LM, } \\
\text { PT, RTW, SE, S }\end{array}$ & Total \\
\hline Laceration & 22 & 5 & 2 & 4 & 33 \\
Concussion & 5 & 1 & 0 & 0 & 6 \\
Sprain & 34 & 12 & 8 & 1 & 55 \\
Fracture & 10 & 3 & 5 & 1 & 19 \\
Burn & 3 & 3 & 0 & 0 & 6 \\
Contusion & 11 & 2 & 2 & 1 & 16 \\
Strain & 2 & 2 & 0 & 0 & 4 \\
Other & 3 & 1 & 0 & 0 & 4 \\
Total & 90 & 27 & 17 & 9 & 143 \\
\hline
\end{tabular}

${ }^{*}$ Ed $=$ Education, JSA $=$ Job Site Assessments, LM = Lifting Mechanics, PT = Postural Training, RTW = Return-To-Work, $\mathrm{SE}=$ Strengthening exercises, and $\mathrm{S}=$ Stretching. 
Creative Commons licensing terms

Author(s) will retain the copyright of their published articles agreeing that a Creative Commons Attribution 4.0 International License (CC BY 4.0) terms will be applied to their work. Under the terms of this license, no permission is required from the author(s) or publisher for members of the community to copy, distribute, transmit or adapt the article content, providing a proper, prominent and unambiguous attribution to the authors in a manner that makes clear that the materials are being reused under permission of a Creative Commons License. Views, opinions and conclusions expressed in this research article are views, opinions and conclusions of the author(s). Open Access Publishing Group and European Journal of Public Health Studies shall not be responsible or answerable for any loss, damage or liability caused in relation to/arising out of conflicts of interest, copyright violations and inappropriate or inaccurate use of any kind content related or integrated into the research work. All the published works are meeting the Open Access Publishing requirements and can be freely accessed, shared, modified, distributed and used in educational, commercial and non-commercial purposes under a Creative Commons Attribution 4.0 International License (CC BY 4.0). 